\title{
MEMÓRIA E ESQUECIMENTO: A CONFIGURAÇÃO \\ DA IDENTIDADE EM “UNACCUSTOMED EARTH”, \\ DE JHUMPA LAHIRI
}

\section{MEMORY AND FORGETTING: AN ANALYSIS OF "UNACCUSTOMED EARTH", BY JHUMPA LAHIRI}

\section{Shirley de Souza Gomes Carreira*}

RESUMO: Este artigo visa à análise do conto "Unaccustomed Earth", de Jhumpa Lahiri, de modo a demonstrar como o texto literário constitui um espaço onde a relação dialética entre memória e esquecimento se entrelaça à questão da identidade cultural do imigrante.

PALAVRAS-CHAVE: memória, esquecimento, migração.

ABSTRACT: This paper aims at analysis of the short story "Unaccustomed Earth", by Jhumpa Lahiri, in order to show the way the literary text comprises a place where the dialectic relationship between memory and forgetting intertwines with the issue of the migrant's cultural identity.

KEYWORDS: memory, forgetting, migration.

* Uniabeu, Rio de Janeiro/RJ. Professora Titular de Literaturas de Língua Inglesa do Curso de Letras. Email: shirleysgcarr@gmail.com. 



\section{MEMÓRIA E ESQUECIMENTO: A CONFIGURAÇÃO DA IDENTIDADE EM “UNACCUSTOMED EARTH”, DE JHUMPA LAHIRI}

My children have had other birthplaces, and, so far as their fortunes may be within my control, shall strike their roots into unaccustomed earth

(Nathaniel Hawthorne).

\section{Introdução}

Na Segunda Dissertação de Genealogia da Moral (1998), Nietzsche analisa as condições sociais de surgimento da memória. O autor sustenta a hipótese de que a memória não é um atributo ou capacidade isolada de um indivíduo, mas uma construção social. A construção da memória decorre de pressões sociais, uma vez que o homem inicialmente age movido pelas forças espontâneas e impulsivas do esquecimento.

Para Nietzsche, o esquecimento é uma força positiva que possibilita uma espécie de relaxamento da consciência, permitindo a insurgência do novo.

A necessidade de viver em grupo, e por ele ser protegido, fez com que o homem inibisse a sua capacidade de esquecer, desenvolvendo a memória, para que, dessa forma, ele se tornasse comprometido com os interesses da coletividade. E é esse compromisso que dá ao homem o sentido de pertencimento. 
A vida de um imigrante é marcada pelos traços da memória. A experiência de viver em um país estrangeiro é sempre a história de um eu dividido, por um lado, preso às tradições de seu país de origem e, por outro, atraído pelo sabor de liberdade que o contato com uma nova cultura concede.

Desde seu primeiro livro, Jhumpa Lahiri, que ganhou o prêmio Pulitzer de 1999 pela coletânea de contos Interpreter of Maladies, tem abordado a experiência do convívio com duas culturas diferentes, bem como o modo de relacionar-se com cada uma delas.

Este artigo visa à análise do conto "Unaccustomed Earth", que dá título ao livro publicado em 2008, de modo a demonstrar como as relações entre memória e esquecimento operam no texto e como essa dialética entrelaça-se à questão da identidade cultural do imigrante.

\section{De onde se enuncia a voz?}

Há alguns anos, com o boom da literatura pós-colonial, o discurso da crítica começou a girar em torno da oposição colonizador/colonizado ou dominador/dominado e os estudos literários passaram a investigar as marcas dessas oposições binárias nas obras dos escritores migrantes, que, em sua maioria, constituíam relatos do choque entre culturas, bem como do processo de integração.

Um aspecto fundamental da experiência migratória é a redefinição das identidades culturais e nacionais, que ocorre quando os indivíduos deixam uma sociedade ou uma cultura e tornam-se parte de outra.

O exílio é uma fratura incurável entre um ser humano e seu lugar natal, cujo pathos, como afirma Said (2003, p. 52), está na perda de contato com a solidez e com a satisfação da terra. Constitui uma estada sofrida no território do não pertencer e caracteriza-se pelo abandono das raízes e do passado. O exilado tenta, a seu modo, reconstituir a sua vida em um novo espaço.

Segundo Said,

[...] grande parte da vida de um exilado é ocupada em compensar a perda de seu espaço natal, criando um novo mundo para governar. Esse novo mundo é artificial e sua irrealidade assemelha-se à ficção. No exílio, o isolamento provoca certo masoquismo narcisista, que resiste aos esforços de melhoramento, aculturação e adesão à outra comunidade (2003, p. 54). 
Claro está que o processo de aculturação não segue um modelo definido e as posturas diante dessa nova realidade diferenciam-se. Assim, é possível distinguir dois modelos: o unidirecional, em que se pressupõe o total abandono das raízes e a aceitação completa da cultura do país de adoção, e o bidirecional, em que há trocas entre o imigrante e a cultura local. A atitude do imigrante ante a nova cultura pode, assim, ser de: integração, quando ele mantém os valores étnicos originais e boas relações com o grupo majoritário; de separação, quando o individuo opta por manter seus valores étnicos, sem procurar estabelecer relações favoráveis com a comunidade dominante; de assimilação, que implica o abandono da própria identidade cultural em favor da comunidade dominante; e de marginalização, quando há a perda total da identidade cultural e a ausência de integração com a comunidade.

Em um mesmo grupo, ou família, as estratégias podem ser diferentes, uma vez que terão de ser levados em consideração aspectos individuais. $\mathrm{O}$ escritor migrante, por exemplo, costuma evidenciar o choque entre culturas. No entanto, as obras escritas por filhos de imigrantes tendem a focalizar a complexidade das relações entre a geração que vivenciou a diáspora e a de seus filhos, nascidos em solo estrangeiro, que, ao contrário dos pais, não têm uma terra natal a lembrar, nem tradições a cultuar.

De acordo com Maurice Halbwachs, a preservação da memória é responsável pela perpetuação de um sentido de identidade e é na sociedade que as pessoas normalmente adquirem, relembram, reconhecem e localizam as suas memórias (2004, p. 38). Assim, ele afirma que é impossível para os indivíduos lembrar qualquer fato de um modo persistente e coerente estando fora do contexto de seu grupo social. A memória individual existe sempre a partir de uma memória coletiva, posto que todas as lembranças são constituídas no interior de um grupo.

Um indivíduo é em parte o resultado de suas próprias experiências e em parte o produto de uma série de normas sociais que são internalizadas por meio da memória coletiva. Assim como o pertencimento a um grupo proporciona material para a memória e impele o indivíduo a lembrar alguns eventos em particular, em detrimento de outros, os grupos também produzem memórias nos indivíduos sobre eventos que, na realidade, estes nunca experimentaram.

Os filhos de imigrantes experimentam essa memória de empréstimo de um modo mais agudo, devido ao fato de não terem usufruído de um contato real com a terra de seus pais. 
Sendo filha de imigrantes, nascida na Inglaterra e educada nos Estados Unidos, Jhumpa Lahiri é o exemplo de um indivíduo “traduzido", expressão utilizada por Salman Rushdie (1991) para designar pessoas a quem a experiência da migração confere uma ótica cosmopolita, que está acima do sentido estrito de pertencimento.

\section{Raízes em solo novo}

O conto que é objeto deste artigo, "Unaccustomed Earth", contém a narrativa do conflito interior de Ruma, filha de imigrantes indianos, nascida na América. Casada e prestes a ter o segundo filho, ela recebe a visita do pai, já aposentado, em sua nova casa em Seattle. A visita desperta na protagonista uma profusão de sentimentos, trazendo à tona velhos ressentimentos e uma reflexão profunda sobre a sua relação com o passado.

Assim como em seus livros anteriores, os personagens de Jhumpa Lahiri são imigrantes em confronto com os filhos, educados na América; exilados que vivenciam duas culturas diferentes sem pertencer de fato a nenhuma; pessoas que, por um lado, estão demasiadamente acostumadas à liberdade de expressão para render-se à tradição, aos costumes de sua terra natal, mas que, por outro lado, não se sentem capazes de abraçar integralmente a cultura de seu novo país.

A história começa com uma retrospectiva das últimas atividades do pai de Ruma: suas viagens pela Europa, depois da aposentadoria. Também revela o desconforto de Ruma diante da brevidade da comunicação entre eles, limitada a umas poucas palavras em cartões de viagem, e o seu ressentimento por ele estar sempre tão distante.

The postcards were the first pieces of mail Ruma had ever received from her father. In her thirty-eight years he'd never had any reason to write to her. It was a one-sided correspondence; his trips were brief enough so that there was no time for Ruma to write back, and besides, he was not in a position to receive mail on his end (...) The cards were addressed to Ruma; her father never included Adam's name, or mentioned Akash. It was only in his closing that he acknowledged any personal connection with them. "Be happy, love Baba", he signed them, as if the attainment of happiness were as simple as that (LAHIRI, 2008, p. 4).

Na juventude, sempre achara extremamente difícil viver de acordo com a tradição indiana. Para tristeza dos pais, Ruma e o irmão, Romi, eram demasiadamente atraídos pela cultura americana. 
Quando começou seu relacionamento com Adam, seu marido, Ruma manteve o namoro em segredo até o dia em que anunciou o noivado. Seus pais interpretaram sua escolha como vergonha das próprias raízes, como uma rejeição das origens.

Mesmo antes do casamento, a relação com os pais tinha sido difícil e tumultuada, tornando-se um frio distanciamento com o passar dos anos. A distância aumentara mais ainda com a mudança para Seattle.

A proximidade da visita do pai leva Ruma de volta ao conflito. No íntimo, ela teme que, ao término das viagens, ele venha para ficar e que a sua presença traga de volta velhos hábitos aos quais ela não está mais acostumada, bem como o passado que ela deixara para trás.

As constantes viagens de Adam, a trabalho, imprimem uma solidão maior ao seu duplo exílio, de suas raízes e da cidade de Nova Iorque, tornando mais séria a ameaça que a visita do pai representa.

De acordo com a tradição indiana, cabe à filha cuidar do pai em sua velhice, mas Ruma não se sente preparada para cumprir o que dela se espera. Ela sabe que a visita ocorrerá no intervalo entre duas viagens e que o próximo destino do pai será Praga.

O leitor percebe, de imediato, a ambiguidade dos sentimentos de Ruma em relação ao pai, pois, ao mesmo tempo em que vigia as notícias quando ele está viajando, com receio de algum acidente aéreo, guarda dentro de si, cuidadosamente, um conjunto de motivos que lhe permitam justificar as próprias atitudes. Após a morte da mãe, ela assumira a obrigação de comunicar-se com o pai todos os dias. Com o passar do tempo, as ligações diárias se tornaram em uma única conversa semanal ao telefone, geralmente aos domingos. Ao contrário da mãe, que quando desejava visitá-la simplesmente avisava a data e o horário da chegada, seu pai telefonara antes, perguntando se podia fazer-lhe uma visita. Este fato demonstra o nível de relacionamento que ela mantinha com ambos.

Ruma tivera uma vida profissional promissora em um escritório de advocacia, mas após as duas semanas de afastamento devido ao luto pela morte da mãe, em decorrência de uma cirurgia mal sucedida, decidira pedir demissão e ficar em casa, cuidando do filho. Na realidade, a renúncia ao exercício da profissão começara bem antes, quando pedira a redução de sua carga horária para meio expediente, após o nascimento de Akash.

Sem que percebesse, Ruma abrira mão de uma condição que lhe dava independência como indivíduo e passara a dedicar-se ao lar, assumindo um papel social idêntico ao de sua mãe. 
There were mornings she wished she could simply get dressed and walk out the door, like Adam. She didn't understand how her mother had done it. Growing up, her mother's example moving to a foreign place for the sake of marriage, caring exclusively for children and a household had served as a warning, a path to avoid. Yet this was Ruma's life now (LAHIRI, 2008, p.11)

A solidão devido à mudança de cidade faz-se sentir de um modo mais profundo quando Ruma vê o pai saltando do carro de aluguel no dia de sua chegada. Ao vê-lo, ela se dá conta de que deixara para trás todas as conexões que tinha; todos os contatos feitos ao longo dos anos.

O pai também lhe causa surpresa, pois naquele momento, envelhecido, em trajes ocidentais, ele parecia mais americano que indiano. Sua imagem agora era cosmopolita, sem nenhum rastro de origem. Fosse ainda viva, a mãe teria vindo com seus sáris coloridos, seus enfeites indianos. Só naquele momento ela consegue perceber o quanto eles tinham sido diferentes.

Ela mesma havia tentado de alguma forma manter um pé no passado, ensinando umas poucas palavras em bengali a Akash, mas o filho crescera e ela não tivera a disciplina necessária para ensiná-lo. Na realidade, o seu mundo era dividido em dois idiomas: o da infância, bengali, e o da idade adulta, o inglês.

By now Akash had forgotten the little Bengali Ruma had taught him when $\mathrm{He}$ was little. After he started speaking in full sentences English had taken over, and she lacked the discipline to stick to Bengali. Besides, it was one thing to coo at him in Bengali, to point to this or that and tell him the corresponding words. But it was another to be authoritative; Bengali had never been a language in which she felt like an adult. Her own Bengali was slipping from her (LAHIRI, 2008, p. 12)

Ao contrário da mãe, que, a exemplo de muitos imigrantes de primeira geração, recusava-se a falar o inglês em família, o seu pai era mais flexível, o que facilitara a assimilação à nova cultura.

Assim como o idioma de seus pais, outros antigos hábitos foram deixados para trás, como, por exemplo, o de retirar o calçado à porta. Aos poucos, outras imagens vêm à sua memória: o desgosto que sua mãe manifestara ainda em vida diante da preferência da filha por roupas ocidentais; a sua previsão de que todas as peças de seu vestuário acabariam em mãos es- 
tranhas quando morresse; a concretização do que ela previra, quando, após a sua morte, Ruma optara por ficar com apenas três dos duzentos e dezoito sáris que possuía, distribuindo o restante entre as amigas da mãe.

Of the two hundred and eighteen saris, she kept only three, placing them in a quilted zippered bag at the back of her closet, telling her mother's friends to divide up the rest. And she had remembered the many times her mother had predicted this very moment, lamenting the fact that her daughter preferred pants and skirts to the clothing she wore, that there would be no one to whom to pass on her things (LAHIRI, 2008, p.17)

Paulatinamente, coisas que nunca pensara antes começam a surgir em sua mente, aos borbotões: o esmero com que sua mãe fazia as tarefas de dona de casa; a excelência de sua habilidade na cozinha, que nunca fora elogiada pelo pai; a sua entrega à família, sem o menor reconhecimento.

A solidão que Ruma experimenta, vivendo em um local distante, acrescida da proximidade do parto, faz com que ela relembre o quanto a presença da mãe lhe trouxera uma sensação de segurança e conforto quando Akash nascera. A mãe, revestida de todo o seu tradicionalismo, de seu apego às raízes, era a sua homeland. A palavra homeland é empregada aqui no sentido atribuído por Rushdie em Imaginary homelands (1991): o lócus onde a identidade é ancorada. Dada a sua natureza mítica, assume características idealizadas, irreais.

Ao leitor não passa despercebido o fato de que, ao longo dos anos, Ruma estabelecera com a mãe ligações paradoxais, pois ao mesmo tempo em que reconhecia nela qualidades que ela mesma jamais viria a ter, rejeitava a sua subserviência à tradição. A essência dessas relações era o próprio conflito que Ruma experimentara a vida inteira, a sua completa dificuldade de entender quem realmente era e a que mundo pertencia.

Essa ambivalência também é experimentada pelo pai de Ruma. Por meio de uma alternância de focalização, o narrador revela ao leitor uma outra versão dos acontecimentos. Na perspectiva do pai, deparamo-nos com um homem de setenta anos, a quem a perda da esposa, o casamento da filha e o distanciamento do único filho homem legaram apenas a instância de estar vivo.

Ao fazer a viagem que Ruma e esposa pretendiam fazer antes da cirurgia que mudara o curso da vida de toda a família, ele buscou dar sentido à própria existência. As amarras haviam se dissolvido. E, em uma das muitas 
viagens que sucederam a primeira, encontrara uma mulher que chamara a sua atenção: a Sra. Bagchi. Assim como Ruma fizera em sua juventude, ele também se absteve de mencionar esse relacionamento. Talvez pelo mesmo motivo: o desejo de não magoar ninguém.

He saw no point in upsetting them, especially Ruma now that she was expecting again. He wondered if this was how his children had felt in the past, covertly conducting relationships back when it was something he and his wife had forbidden, something that would have devastated them (LAHIRI, 2008, p.19).

Através do seu olhar, a mudança que se opera em Ruma assume proporções mais intensas. A jovem rebelde do passado tornava-se cada vez mais parecida com a mãe:

When he was finished he poked his head into Akash's room and found both the boy and Ruma asleep. For several minutes he stood in the doorway. Something about his daughter's appearance had changed; she now resembled her mother so strongly that he couldn't bear to look at her directly (...) her face was older now, as his wife's had been, and the hair was beginning to turn gray at her temples in the same way, twisted with an elastic band into a loose knot. And the features, haunting now that his wife was gone -the identical shape and shade of the eyes, the dimple on the left side when they smiled (LAHIRI, 2008, p. 28).

Em sua viagem à Europa, ele pudera recordar-se dos seus primeiros dias na América; a dificuldade de comunicar-se em um país estrangeiro, sem conhecer o idioma. Lembrava-se, agora, estando em Seattle, de como a vida tinha sido dura, de como era sombrio e apertado o apartamento em que vivera com a esposa e os filhos ainda bebês. Eles haveriam de lembrar-se apenas da casa espaçosa que adquiriram depois, quando ele terminou o $\mathrm{PhD}$ em bioquímica e obteve uma boa colocação.

Ruma e Adam viviam em uma casa infinitamente superior àquela que pudera dar à esposa e aos filhos. A casa em que os criara tivera de ser vendida, pois, sozinho, já não fazia sentido viver lá. Ainda que os amigos lhe sugerissem seguir o costume e morar com a filha, ele sabia que não poderia fazê-lo. Também ele havia deixado os próprios pais na Índia e partido. Nem mesmo a morte do pai o fizera retornar. Havia feito a sua escolha e agora Ruma fazia a dela. 
O contraste de atitudes entre ele e a esposa fica evidente quando ele pensa que se ele tivesse morrido, ao invés dela, ela não hesitaria em mudar-se para a casa da filha. Eram muito diferentes: ela era alegre, necessitava estar perto das pessoas; ele era soturno e gostava da solidão.

Assim como a filha, que tantas vezes fora acusada de romper as amarras que a ligavam à família, ele agora reconhece que também fez o mesmo. Mudara-se, depois do falecimento da esposa, para outra localidade no mesmo estado; perto o bastante para não se sentir novamente estrangeiro, mas longe o suficiente para separar-se de sua antiga vida, das velhas amarras.

Com a clareza que o tempo concede, ele é capaz de perceber que sua companheira de viagem, a Sra. Bagchi, havia amado muito mais o marido com quem convivera apenas dois anos do que ele amara a esposa em uma união de quase quarenta. Percebe também que não é o amor que o impele na direção daquela mulher, mas a força do hábito de conviver com alguém.

A sua mudança também não passa despercebida à filha. Intimamente, ela percebe que a morte de sua mãe não lhe trouxera a mesma dor que ela sentira; ao contrário, parecia ter-lhe devolvido uma alegria de viver.

É um pai desconhecido que lhe aconselha a voltar a trabalhar, a não viver só para os filhos, como sua mãe fizera. Um pai que nunca lhe contara o quanto as cobranças da esposa, a falta de reconhecimento dela diante do esforço que fazia para manter a família, o entristeceram e destruíram a cumplicidade que um dia tiveram. Um pai que receava que ela repetisse a frustração da mãe e se tornasse tão infeliz quanto ela fora. Um pai que dispensava a Akash uma atenção que nunca dera aos próprios filhos.

A história passa a ser uma sucessão de descobertas de parte a parte. A oscilação entre a memória e o esquecimento tem o vulto de uma dialética ainda mais complexa, entre ater-se às raízes ou permitir-se a mudanças.

Pouco antes de sua partida, o pai decide plantar um jardim e convida o neto a ajudá-lo. Ao longo da empreitada, ele vai ensinando ao menino os nomes dos objetos em bengali. A relação entre avô e neto solidifica-se ao ponto de fazer Ruma pensar que, pela primeira vez na vida, seu pai descobrira o sentido de amar outra pessoa.

A certeza de que jamais veria o neto crescer traz-lhe certa nostalgia, confirmada pela experiência de quem viu os filhos partirem, de quem foi filho um dia e fez o mesmo, sem olhar para trás.

Ante esse pai que se revela tão diferente e tão mais sensível, Ruma decide convidá-lo a ficar. Ainda que tentado a aceitar, por apego ao neto, ele recu- 
sa. Ficar seria tornar-se novamente parte de uma história, seria criar amarras que já haviam se dissolvido, e mesmo o neto que agora lhe causava a dúvida haveria de esquecê-lo logo, como os filhos fizeram.

Ao partir, o pai deixa, sem perceber, um envelope, com uma carta em bengali, destinada à Sra. Bagchi, que não conseguira pôr no correio. Incapaz de lê-la, pois nunca dera valor aos esforços da mãe para aprender o idioma, Ruma adivinha o seu conteúdo. A descoberta tem para ela um sabor amargo. Durante toda a estada do pai em sua casa, não conseguira perguntar-lhe se havia um dia amado sua mãe, se sentia falta dela. A carta dá-lhe toda a dimensão da ausência, como se fosse uma segunda morte.

O pai optara pelo esquecimento de modo a experimentar o novo. Diante do embate entre o passado e o presente, Ruma aquiesce e decide enviar a carta ao seu destinatário. Aos seus olhos, a América é exatamente como pensava na sua juventude: a terra onde novas identidades podem ser construídas; pautadas no presente e no futuro, livres da opressão das amarras de uma memória que já não é mais a sua.

\section{Conclusão}

O olhar da autora sobre a experiência da migração atualiza as reflexões sobre a memória coletiva, pois, para ela, o local de pertencimento é aquele que permite ao indivíduo ser o que é, a par do seu local de nascimento, das tradições que lhe foram impostas ou transmitidas.

A dialética da memória e do esquecimento acompanha o indivíduo migrante, que, continuamente, se debate entre passado e presente. No entanto, sendo uma imigrante de segunda geração, Lahiri imprime a essa dialética nuances próprias. "Unnacustomed Earth" não busca rememorar tradições ou narrar o processo de aculturação. É uma narrativa que expõe os conflitos inerentes a uma identidade reconhecidamente híbrida, fruto de negociações entre diferentes culturas.

A memória sociocultural coletiva dos povos da diáspora constitui-se de laços com uma terra natal distante e idealizada. Jhumpa Lahiri concede a si mesma o privilégio de estabelecer esses laços de forma diferenciada. $\mathrm{O}$ seu estilo de narrar, fruto da transculturação, transpira a fluidez das identidades alternativas. É com o duplo olhar de quem efetivamente habita o terceiro espaço, descrito por Homi Bhabha, que ela narra a história de suas personagens.

A epígrafe que introduz o conto, uma citação de Hawthorne, sugere que o destino dos homens pode ser mudado quando eles lançam suas sementes 
em um solo novo. Esse solo é justamente o espaço em que novas relações de pertencimento vão sendo construídas, não mais pautadas na cultura da terra natal, nem tampouco na cultura do país de adoção, mas na crença de que pertencemos ao lugar em que queremos estar.

\section{Referências Bibliográficas}

HALBWACHS, Maurice. A Memória Coletiva. São Paulo: Ed. Centauro, 2004.

HEDGE, M. G. Movements and migration: tales from the third space. In: SHUKLA, S.; SHUKLA, A. Migrant voices in literatures in English. New Delhi: Sarup \& Sons, 2006.

LAHIRI, Jhumpa. Unaccustomed earth. New York: Vintage Books, 2008. . Interpreter of Maladies. New York: Houghton Mifflin Company, 1999.

NIETZSCHE, Friedrich Wilhelm. Genealogia da moral: uma polêmica. São Paulo: Companhia da Letras, 1998.

POLLAK, Michael. Memória, esquecimento, silêncio. Estudos Históricos, Rio de Janeiro, v. 2, n. 3, 1989.

RICOEU, Paul. Memory, History and Forgetting. Chicago: University of Chicago Press, 2006.

RUSHDIE, Salman. Imaginary homelands. Essays and Criticism 1981-1991. London: Granta/Penguin, 1991.

SAID, Edward. Reflexões sobre exílio e outros ensaios. Trad. Pedro Maia Soares. São Paulo: Companhia das Letras, 2003. 